\title{
Acute type A aortic dissection: timeline between onset and treatment
}

\author{
Marie De Vos^, Willem Ranschaert, Wim Vergauwen, Eric Graulus, Paul Verrelst, Marc Schepens \\ General Hospital Sint-Jan Brugge-Oostende, Bruges, Belgium \\ Contributions: (I) Conception and design: M Schepens; (II) Administrative support: M De Vos, M Schepens; (III) Provision of study materials or \\ patients: M Schepens; (IV) Collection and assembly of data: M De Vos, M Schepens; (V) Data analysis and interpretation: M De Vos, M Schepens; (VI) \\ Manuscript writing: All authors; (VII) Final approval of manuscript: All authors. \\ Correspondence to: Marie De Vos. Ruddershove 10, 8000 Bruges, Belgium. Email: marie.devos@azsintjan.be; medvos1@gmail.com.
}

Background: Patients with acute aortic dissection are affected with high early mortality. However, only limited data is available to delineate the factors that contribute to initial delays in establishing the diagnosis and treatment.

Methods: In this single-centre, retrospective analysis, we reviewed 52 consecutive patients with acute type A aortic dissection (ATAAD) presenting at our institution (General Hospital Sint-Jan Bruges, Belgium) from January 2009 to October 2019. After thorough review of all medical records, a timeline was drawn for every patient, reflecting time delays from onset of symptoms to diagnosis and treatment. These data were supplemented with patients clinical characteristics. Statistical analysis using the Mann-Whitney U test $(\mathrm{P}<0.05)$ and the Kruskal-Wallis test $(\mathrm{P}<0.05)$ for independent samples were used.

Results: The median time elapsed from 'onset-to-presentation' was $126.5 \mathrm{~min}$ (61-300 $\mathrm{min})$, from 'presentation-to-diagnosis' $85.5 \mathrm{~min}$ (35.5-209 min), from 'diagnosis-to-surgery' $210 \mathrm{~min}$ (74-320.75 $\mathrm{min}$ ) and from 'onset-to-knife' $600 \mathrm{~min}$ (337.5-1,125 min). The time from 'diagnosis-to-surgery' was significantly longer $(\mathrm{P}<0.05)$ than any of the other time-related variables. Gender, the mean amount of imaging studies needed to reach definitive diagnosis and the imaging study that provided definitive diagnosis had a significant influence on the 'onset-to-knife' time. Only the amount of imaging studies needed to reach definitive diagnosis was significantly related to the 'presentation-to-diagnosis' time. We report a 30-day mortality of $7.7 \%$ and an in-hospital mortality of $11.5 \%$.

Conclusions: Clinical knowledge and awareness remain very important to contribute to an early admission, followed by sharp and accurate diagnosis to improve outcome. Improvement in logistics should lead to shorter 'diagnosis-to-surgery' time. Owing to the time-dependent properties of ATAAD management, a (national) system of aortic dissection care should be drafted.

Keywords: Acute type A aortic dissection (ATAAD); timeline; delay in diagnosis and treatment

Received: 10 February 2020; Accepted: 21 April 2021; Published: 20 July 2021.

doi: 10.21037 /jovs-20-54

View this article at: http://dx.doi.org/10.21037/jovs-20-54

^ ORCID: 0000-0001-6114-6538. 


\section{Introduction}

In life, time and even seconds, do matter. Especially in certain domains of medicine, losing time means losing lives. Stroke and acute coronary syndrome (ACS) are well-known examples. In cardiothoracic surgery, acute type A aortic dissection (ATAAD) is the most life-threatening emergency, requiring immediate surgical intervention. The incidence of ATAAD is 2.53 cases per 1,000,000 people per year (1). Mortality rates prior to hospital arrival range between 20 $60 \%(2,3)$. When presenting alive to a hospital, mortality rates of $10.3 \%$ in the first $6 \mathrm{~h}, 21.4 \%$ within $24 \mathrm{~h}$ and $45.2 \%$ within 30 days are reported $(2,3)$, which is similar to the earlier observed mortality rate of $1 \%$ per hour during the initial 48 hours by Anagnostopoulos et al. (4) Although the methodology of the older literature on incidence and mortality of ATAAD could be criticized, they are confirmed in more recent reports (5-10). As pathogenesis is reasonably well defined, we know that patients die from aortic rupture, tamponade, acute aortic insufficiency and malperfusion syndromes (11). In contrast the 30-day survival rate for patients with efficient diagnosis and optimal care approaches 90\% (12). We know from the International Registry of Acute Aortic Dissection (IRAD) (2) that the median time from presentation to diagnosis for all acute aortic dissection patients is over 4.3 hours. Contrary to what one might expect, death prior to hospital arrival or within 6 and $24 \mathrm{~h}$ of admission did not change much over time, indicating that advancement in diagnostic technology and urgent medical care had only minimal effects on early mortality $(4,13)$. This can be explained because of the relative infrequency of ATAAD, together with clinical presentations that may vary and mimic more common problems such as ACS (which could lead to exposure to antithrombotic agents) or stroke (14). There are few studies, trying to define clinical and diagnostic factors that could help reduce time delay between onset of symptoms, diagnosis and surgery $(2,15-18)$. They show that improved physician awareness of typical and atypical presentation of acute aortic dissection, low threshold for tomographic imaging and prompt transport to a tertiary hospital or department of cardiac surgery where they can initiate surgery immediately could reduce crucial time variables. For now, it seems that up to $35 \%$ of patients are misdiagnosed on initial presentation (1). Once diagnosed, delays to surgery are mainly due to hospital organization in providing an available operating theatre with trained personnel or in absence of the necessary facilities or expertise, by transfer to a tertiary care centre (19). A promising approach in reducing delay is demonstrated by a multidisciplinary, regional protocol to standardize the care for $\operatorname{ATAAD}(2,16)$.

It is important to remember that delay to surgery does not automatically indicate a failure of care systems. As previously suggested in literature, some subsets of patients may benefit from delayed operation in order to perform additional imaging or address comorbidities (20-24).

However, an accurate diagnosis made in a timely manner is still the best opportunity for a positive health outcome because clinical decisions and treatment will be tailored to a correct understanding of the problem (25). This is translated in the door-to-needle time of less than 60 minutes in case of stroke and ACS.

The purpose of this single-centre retrospective study of all ATAADs over a 10 -year period was first to determine delays in presentation, diagnosis and treatment, which are still encountered despite unprecedented possibilities and technologies in medicine and secondly to clarify factors related to these delays and come up with possible solutions to avoid them in the future. We present the following article in accordance with the STROBE reporting checklist (available at https://jovs.amegroups.com/article/ view/10.21037/jovs-20-54/rc).

\section{Methods}

\section{Study design}

All patients who presented at our institution between January 2009 and October 2019 with an ATAAD were included in this single-centre retrospective study. Aside from patient characteristics, a timeline was drawn for each patient including the time of onset of symptoms, arrival at the referring hospital, arrival at our own hospital (General Hospital SintJan, in Bruges, Belgium), time of definitive diagnosis and start of surgery. All these data were obtained through thorough medical record review. Because of the retrospective design and the data retrieved from hospital medical record system only, informed consent was not required. Patient's personal data were secured. The study was conducted in accordance with the Declaration of Helsinki (as revised in 2013). The study was approved by the institutional ethics board at General Hospital Sint-Jan, in Bruges, Belgium (B2020049000030).

\section{Statistical analysis}

Statistical analysis was performed using SPSS v26 (IBM 
Corp., Armonk, NY). Regarding the time-related variables, the Kruskal-Wallis test $(\mathrm{P}<0.05)$ and the Mann-Whitney $\mathrm{U}$ test $(\mathrm{P}<0.05)$ was used for non-parametric, independent samples.

\section{Results}

Between January 2009 and October 2019, 52 patients with ATAAD were treated at the department of cardiac surgery in General Hospital Sint-Jan, Bruges, Belgium. Results are summarized in Table 1.

\section{Patient characteristics}

The mean age was 66 years (22-89 years). There were 16 female and 36 male patients. Medical history related to ATAAD was negative in $40 / 52$ patients $(76.9 \%)$. The remaining 12 patients had known annuloaortic ectasia $(2 / 12)$, aortic aneurysm (1/12), aortic dilatation (1/12), aortic valve insufficiency grade I-II (1/12), polymyalgia rheumatica $(2 / 12)$, psoriasis arthritis (1/12), rheumatoid arthritis (1/12), previous cardiac surgery $(2 / 12)$ and refractory hypertension $(1 / 12)$. The majority of patients did not take or receive any antithrombotic therapy [38/52 (73.1\%)]. However 7/52 patients $(13.5 \%)$ received dual antiplatelet therapy shortly before surgery and $5 / 52(9.6 \%)$ were on acetylsalicylic acid preoperatively and only $1 / 52$ (1.9\%) was on clopidogrel.

\section{Signs and symptoms}

The most predominant symptom at presentation was retrosternal pain, present in $39 / 52$ patients $(75 \%)$. The nature of the pain was reported as 'abrupt' in the majority of patients [46/52 (88.5\%)]. Syncope is the second most common symptom present in 7/52 (13.5\%), followed by interscapular pain and abdominal pain in 6/52 (11.5\%). Other symptoms are paresis in a lower limb, stroke, coma, nausea \& vomiting, a fall and a newly diagnosed heart murmur (Figure 1).

Preoperative intubation occurred in $7 / 52$ patients (13.5\%), 4/52 (7.7\%) endured CPR, 10/52 (19.2\%) were in shock and 9/52 (17.3\%) developed a cardiac tamponade.

\section{Laboratory tests and electrocardiogram}

Troponin levels were determined in 41 subjects and were positive in only $4 / 52(7.7 \%)$.

D-dimers were determined in $29 / 52$ patients $(55.8 \%)$. In
$27 / 29$ patients $(93.1 \%)$ they were elevated.

Ischaemia on electrocardiogram was seen in only $3 / 52$ patients (5.7\%).

\section{Imaging studies}

One third of patients was diagnosed using 1, 2 or 3 imaging studies, respectively 16/52 (30.8\%), 19/52 (36.5\%) and $15 / 52(28.8 \%)$. The mean variety of imaging studies needed to establish the definitive diagnosis was 1.73 . The first imaging study performed after initial evaluation of the patient was a computed tomography of the chest in almost half of the patients [24/52 patients (46.2\%)]. The second most prevalent imaging study was a chest X-ray in $17 / 52$ patients (32.7\%). Other imaging studies were less frequent, including abdominal $\mathrm{X}$-ray, computed tomography of the abdomen, abdominal echography, transthoracic echocardiography and coronary angiography.

Definitive diagnosis was reached after performing a computed tomography of the chest in $48 / 52$ patients (92.3\%), followed by coronary angiography in $2 / 52$ (3.8\%) and transthoracic and transoesophageal echocardiography both in $1 / 52(1.9 \%)$.

\section{Outcome}

We report a 30 -day mortality of $7.7 \%$ and an in-hospital mortality of $11.5 \%$. There was no significant difference in 30-day mortality or in-hospital mortality between the long or short 'onset-to-knife' time or 'presentation-to-diagnosis' time (Table 1).

\section{Timeline}

The main focus of our study was reporting the delays between onset of symptoms and start of surgery. Therefore, a timeline was drafted for every patient (Figure 2). We calculated the 'onset-to-presentation' time (= time from onset of symptoms to presentation at a hospital), the 'presentation-to-diagnosis' time (= time from presentation at a hospital to definitive diagnosis), the interhospital transfer time (= time elapsed from initial transfer call to arrival at our hospital), the 'diagnosis-to-surgery' time (supplemented with the 'arrival-at-our-institution-tosurgery' time ) and the 'onset-to-knife' time (= total sum of 'onset-to-presentation' time, 'presentation-to-diagnosis' time and 'diagnosis-to-surgery' time). The 'onset-topresentation' time and the 'presentation-to-diagnosis' 


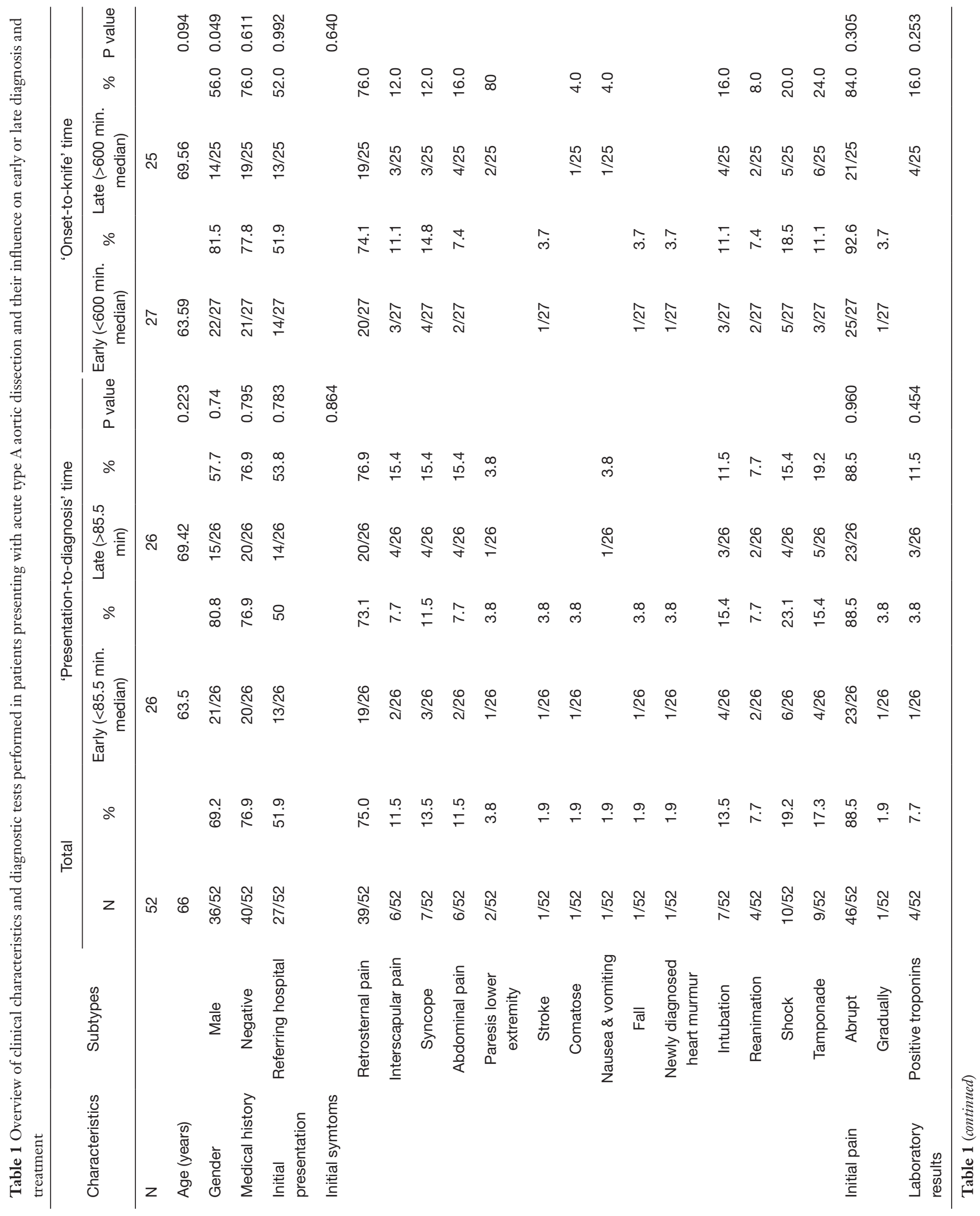




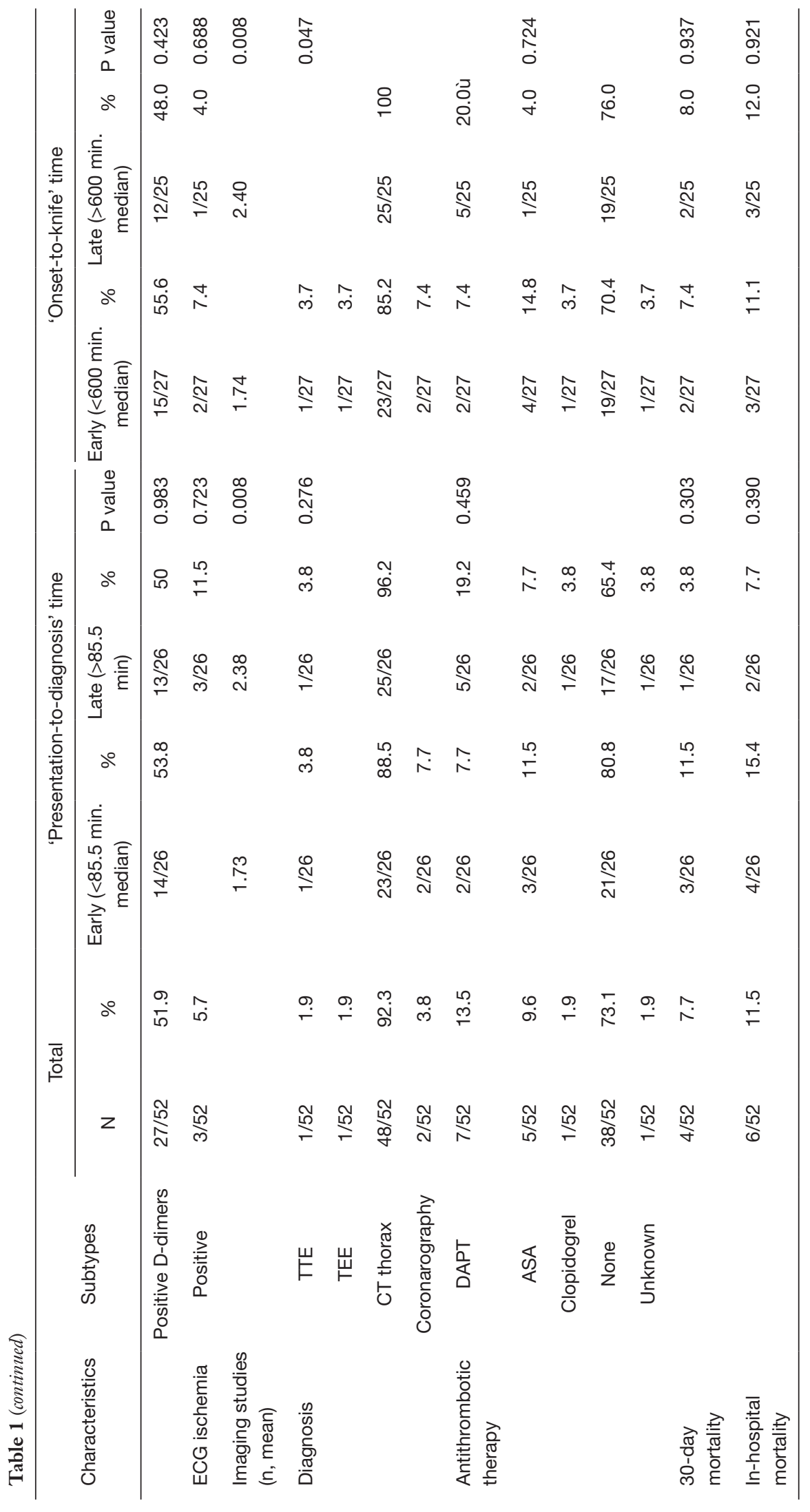




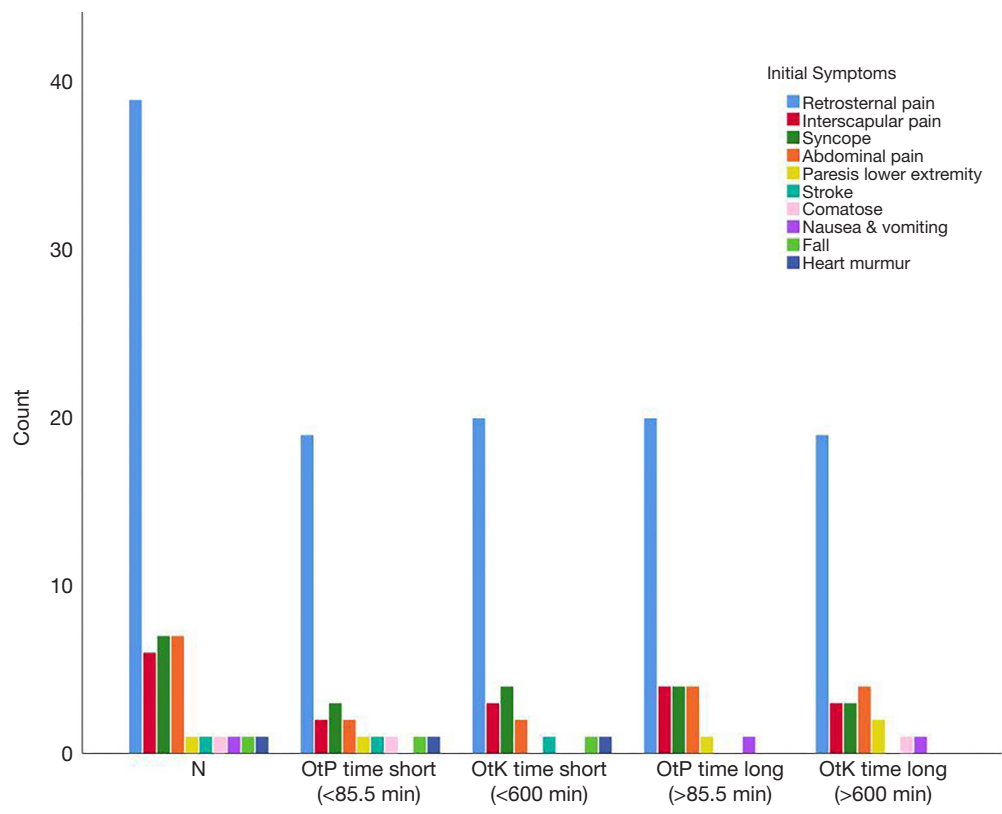

Figure 1 Overview of initial symptoms, stratified between 'short' and 'long' 'onset-to-presentation' time and 'onset-to-knife' time. N, results of total sample size; OtP time, 'onset-to-presentation' time; OtK time, 'onset-to-knife' time.

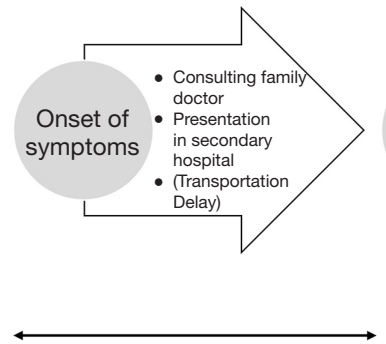

Pre-hospital delay
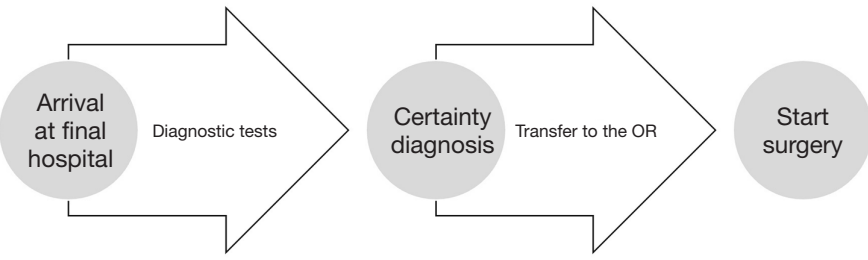

In-hospital delay

Total delay or

'Onset-to-knife' time

Figure 2 Timeline of delays encountered from onset of symptoms to start of surgery in patients with acute type A aortic dissection.

time was subdivided regarding presentation at our own institution or at a surrounding/referring hospital. More than half of the patients (27/52 or $51.9 \%)$ were referred after admission and diagnosis at a surrounding/referring hospitals. The remaining $48.1 \%$ presented at our own centre directly. The median time was calculated for all of the time-related variables above. They are summarized in Table 2 and visualized in Figure 3.

Statistical analysis shown in Table 3 revealed a significantly longer time interval from 'diagnosis-to-surgery' compared to all the other time-related variables reported.

There was no statistical significant difference between the 'onset-to-presentation' time or the 'presentation-todiagnosis' time at a referring hospital compared to our institution.

There was a median pre-hospital delay of $126.5 \mathrm{~min}$ (61$300 \mathrm{~min}$, interquartile range), a median interhospital delay of $90 \mathrm{~min}(67-136.5 \mathrm{~min})$ and a median in-hospital delay of $210 \mathrm{~min}(132.5-309.75 \mathrm{~min})$. This resulted in a median 'onset-to-knife' time of $600 \mathrm{~min}$ (337.5-1,125 min). 
Table 2 Overview of the delays encountered in patients with acute type A aortic dissection

\begin{tabular}{|c|c|c|c|}
\hline Delay [time (min)] & Q25 & Q75 & Median \\
\hline Referring hospital & 61.25 & 285 & 126.5 \\
\hline Our institution & 61 & 718 & 117 \\
\hline 'Presentation-to-diagnosis' time & 35.5 & 209 & 85.5 \\
\hline Our institution & 24 & 460 & 64 \\
\hline Interhospital transfer time & 67 & 136.5 & 90 \\
\hline 'Arrival-at-our institution-to-surgery' time & 74 & 320.75 & 144.5 \\
\hline 'Diagnosis-to-surgery’ time & 132.5 & 309.75 & 210 \\
\hline
\end{tabular}

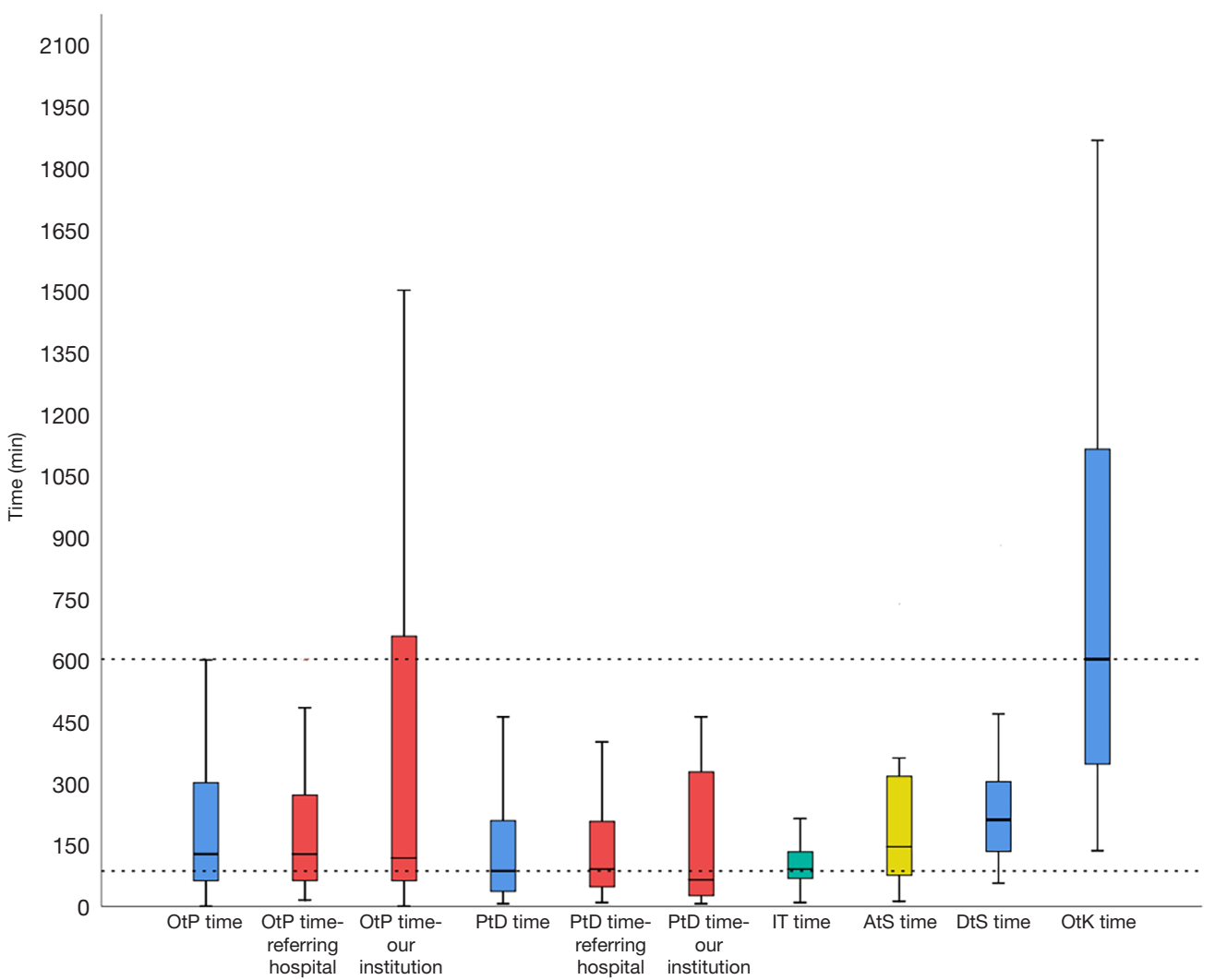

Figure 3 Boxplot of the different time delays encountered in patients presenting with acute type A aortic dissection, resulting in a 'onsetto-knife' time with a median of $600 \mathrm{~min}$. OtP time, 'onset-to-presentation' time; PtD time, 'presentation-to-diagnosis' time; IT time, interhospital transfer time; AtS, 'arrival-at-our-institution-to-surgery' time; DtS time, 'diagnosis-to-surgery' time; OtK time, 'onset-to-knife' time. 
Table 3 Results of statistical analysis of the delays encountered in patients with acute type A aortic dissection

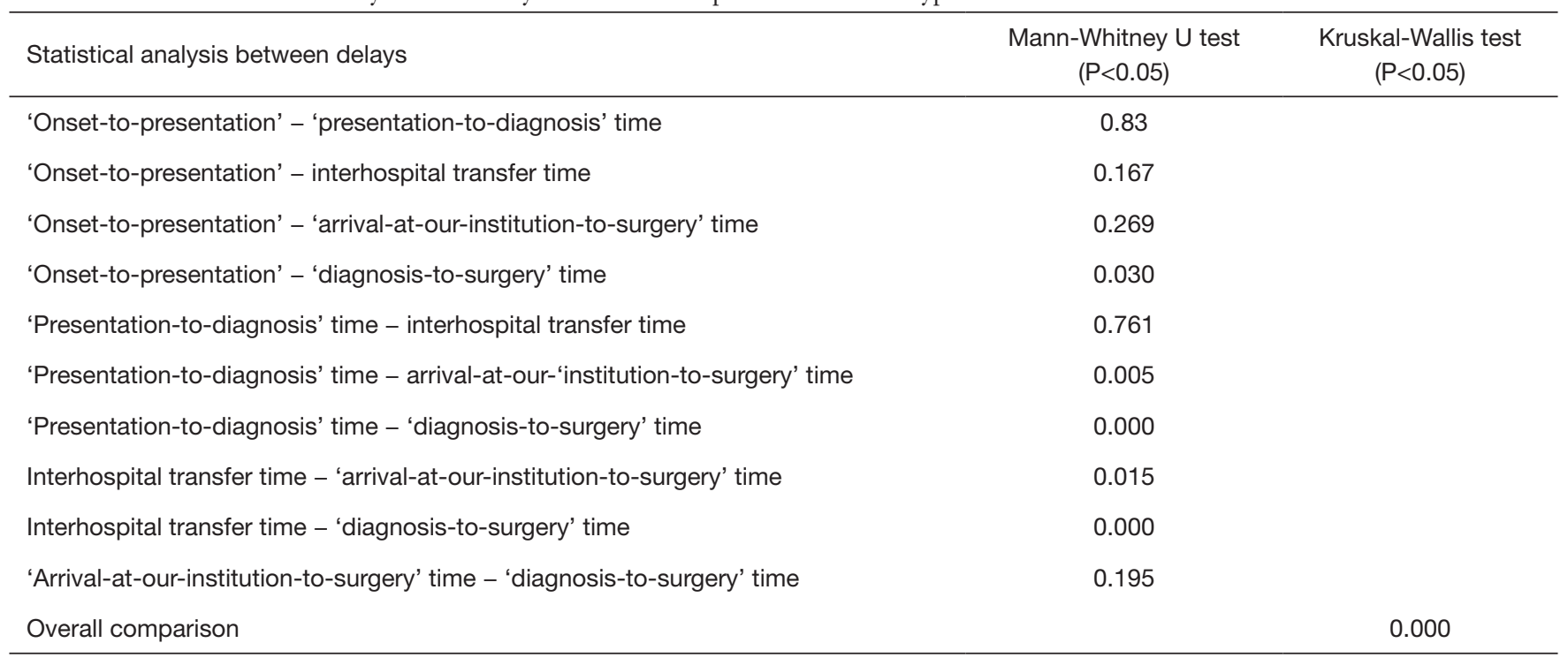

To determine which factors contribute to a tardy or quick 'onset-to-knife' time, we grouped the variable 'onset-to-knife' time into a short, i.e., less than $600 \mathrm{~min}$ [median 'onset-to-knife' time)] and a long time interval of more than $600 \mathrm{~min}$. Results are presented in Table 1 and seen in Figure 4.

We found statistical significance for gender, in favour of a short 'onset-to-knife' time in males $(\mathrm{P}=0.049)$ (Figure 4A), the variety of imaging studies needed to reach definitive diagnosis (more imaging studies in the long 'onset-to-knife' time) $(\mathrm{P}=0.008)$ (Figure $4 B)$ and in the imaging study that led to definitive diagnosis $(\mathrm{P}=0.047)$ (Figure $4 C$ ).

The same analysis was done regarding tardy and quick 'presentation-to-diagnosis' time. A short 'presentation-todiagnosis' time was defined as less than 85.5 min (median 'presentation-to-diagnosis' time). A long 'presentation-todiagnosis' time is greater than $85.5 \mathrm{~min}$. We could only find statistical significance in the variety of imaging studies needed to reach definitive diagnosis (Figure 4D,E,F).

Finally we looked at the evolution in 'presentation-todiagnosis' time and 'onset-to-knife' time over the 10-year period. The result was not significant and is visualised in Figure 5 .

\section{Discussion}

In any medical emergency, the patients experience a range of delays between onset of symptoms, diagnosis and treatment. Regarding the delays observed in ATAAD, literature is scarce $(2,15-18)$.

In the pre-hospital phase the 'onset-to-presentation' time is determined by the lack of recognition or appropriate response to initial symptoms, initially contacting a nonemergency health service/family doctor and delay in transport to the hospital. Regarding the pre-hospital phase for ATAADs, we report a median 'onset-to-presentation' time of $126.5 \mathrm{~min}$ or slightly more than 2 hours. As we live in a small country, transportation delay is assumed to be insignificant. A possible solution for reduction of this delay are educational campaigns to increase patient and bystander awareness. As ATAAD is still a very rare (but also very lethal) condition, which often mimics other medical emergencies like stroke or ACS, it is our believe that raising public awareness is very difficult. Evaluating the effect of such existing campaigns for stroke could not show a reduction in time to presentation (26).

A previous study reported on the delay from diagnosis to surgery in transferred ATAADs (16). They found a significant time delay in patients who were transferred and this was explained by the interhospital transfer time and a longer 'presentation-to-diagnosis' time at the referring hospital. In our series the median interhospital transfer time was $90 \mathrm{~min}$ or 1.5 hours. 'Presentation-todiagnosis' time did not differ significantly between our institution and the referring hospitals in contrast to the results reported by Harris et al. (2) and Froehlich et al. (16). This could be explained by our small sample size and the insignificance of interhospital transfer time in our country. 

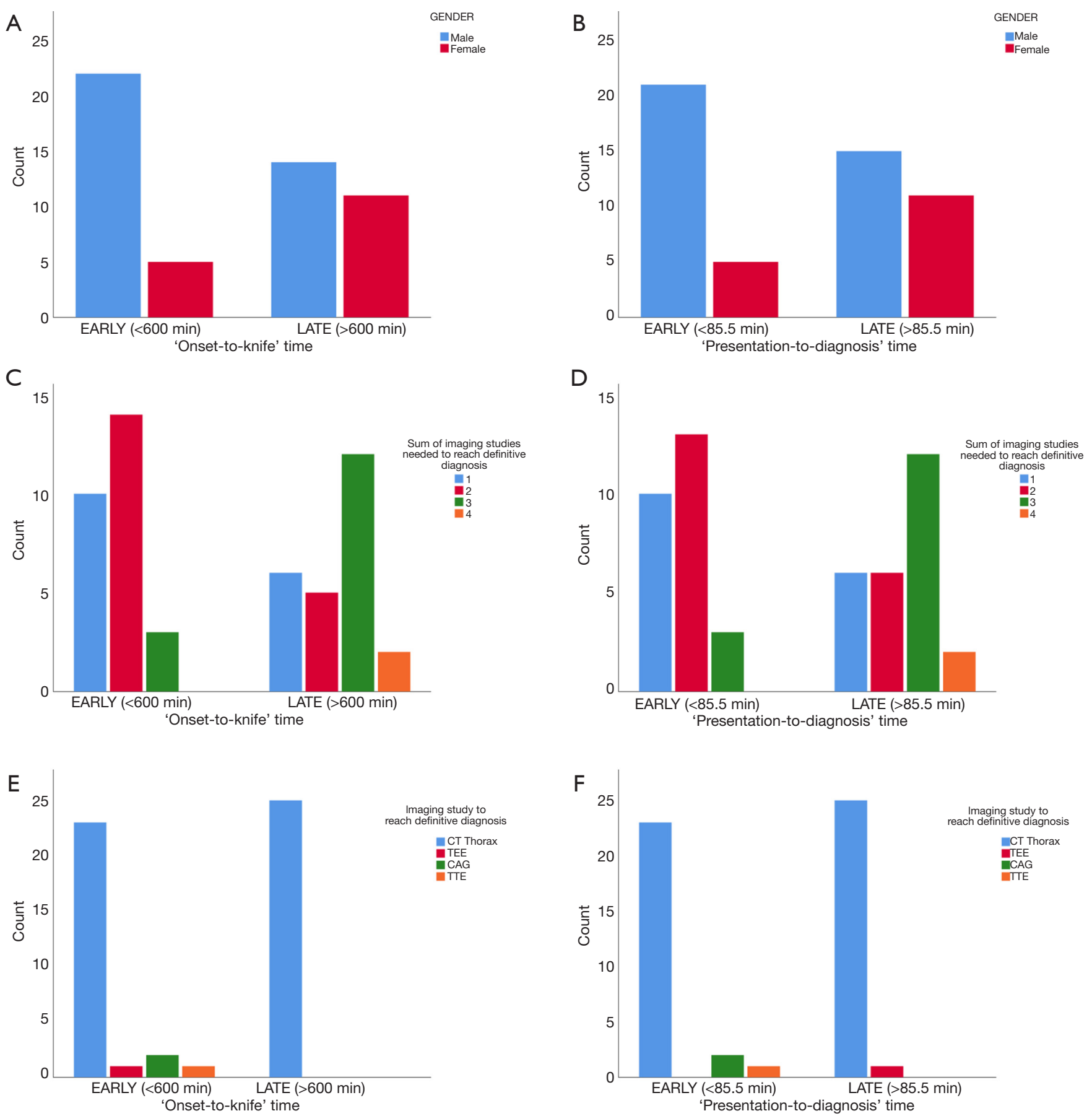

Figure 4 Factors influencing early or late diagnosis and/or treatment in patients presenting with acute type A aortic dissection. Gender, sum of imaging studies needed to reach definitive diagnosis and imaging study to reach definitive diagnosis. (A) Male gender has a significant higher chance at a short 'onset-to-knife' time $(\mathrm{P}=0.049)$. (B) The more imaging studies are requested/performed, the higher chance at a long 'onset-to knife' time ( $\mathrm{P}=0.008)$. (C) Definitive diagnosis is nearly always reached after CT thorax, but transthoracic/transoesophageal echocardiography (TTE/TEE) or coronary angiography may lead to a shorter 'onset-to-knife' time (P=0.047). (D) The 'presentation-todiagnosis' time is not significantly affected by gender. (E) The more imaging studies are requested/performed, the higher chance at a long 'presentation-to-diagnosis' time $(\mathrm{P}=0.008)$. (F) Definitive diagnosis is nearly always reached after CT thorax, but this does not significantly influence the 'presentation-to-diagnosis' time. 


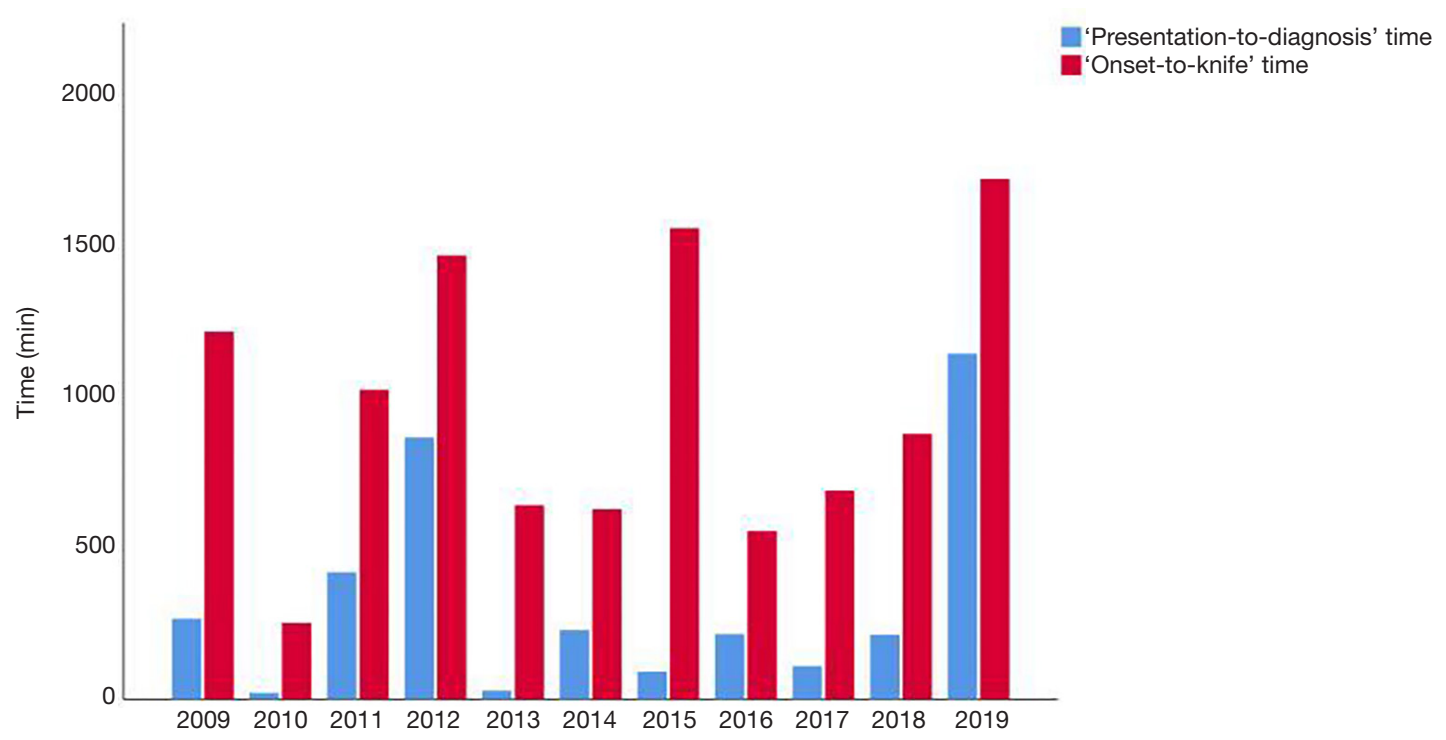

Figure 5 'Presentation-to-diagnosis' time and 'onset-to-knife' time over a 10-year period.

It is worth mentioning that in only 2 patients, the definitive diagnosis was not established at the referring hospital before transportation. One was referred because of cardiac tamponade and the other because of the initial diagnosis of an acute type $B$ aortic dissection.

In-hospital delays depend on the initial interpretation of symptoms and the clinical response which includes ordering the appropriate diagnostic test in a timely manner. This is especially true when symptoms are insidious or mimic more common medical emergencies. In our series, the median 'presentation-to-diagnosis' time is $85.5 \mathrm{~min}$ or approximately 1.5 hours. Compared to the results of the IRAD (2) and Rapezzi et al. (18), which report a time delay of 4.3 hours and 5.5 hours respectively, our time delay seems shorter. Nevertheless, raising clinical awareness of the variety of initial symptomatology in ATAAD is important to reduce delays and by consequence improve patient outcome. Initial misdiagnosis and treatment of more common aetiologies like ACS (17) can lead to administration of antithrombotic agents with a consequently high risk of peri- and postoperative bleeding (27). Coronary angiography can be hazardous in ATAAD (14). However, it is worth mentioning that since the frequency of ACS greatly outnumber the number of dissections, it is appropriate for emergency physicians to focus on this diagnosis in patients presenting with chest or back pain $(28,29)$. It has to be kept in mind that in many cases of ATAAD, electrocardiographic repolarization abnormalities and/or increased troponin levels do reflect coexistent myocardial ischemia with a multifactorial pathogenesis (17).

We analysed the initial symptoms and its influence on 'presentation-to-diagnosis' time and the 'onset-to-knife' time, but could not find a significant relation. This is in contrast to other literature reports, stating that patients experiencing severe symptoms like hypotension, shock and cardiac tamponade receive more swift diagnosis and treatment because of the life-threatening situation $(2,16)$. Atypical presenting symptoms, initial suspicion of ACS or a pulmonary aetiology and presentation to a nontertiary care hospital all may contribute to a late diagnosis of ATAAD $(2,15)$. Again, we attribute our results to the small sample size.

We did find that female patients have a higher chance to have a long 'onset-to-knife' time, which was also found in the IRAD (7). We have no unequivocal explanation for this recurring finding. However, it is known that cardiovascular disease in women is more often under-treated, less well studied compared to men and that they have a worse outcome. In addition, they often present with atypical complaints, which means a broader diagnostic landscape and a longer timeframe to find the correct diagnosis (30).

Although the main value of laboratory testing in ATAAD is exclusion of other diseases, D-dimer analysis should be part of the initial assessment of patients with suspected ATAAD and with chest pain in general (31). D-dimer testing has a reported sensitivity of almost $100 \%$ and a 
specificity of $68.8 \%$ (31). D-dimer concentration was determined in only $55.8 \%$, there is room for improvement, especially because a negative result makes the presence of the disease unlikely.

Regarding imaging studies, definitive diagnosis was reached by computed tomography in $92.3 \%$. In the long 'onset-to-knife' time we found a significant higher number of imaging studies performed before reaching definitive diagnosis. Although the computed tomography is reported as the preferred initial imaging modality (2), it is also known to delay the time to surgery (16). This statement explains our result that the definitive diagnosis was reached after performing computed tomography in all cases with a tardy 'onset-to-knife' time, whereas time can be saved by other, less time-consuming imaging studies like transthoracic echocardiography. This significant result is in contrast with the study by Strauss et al. (15), which report a lower incidence of computed tomography in the tardy 'onsetto-knife' time, with more time consuming alternative imaging studies like magnetic resonance. Transoesophageal echocardiography can more accurately confirm an ATAAD, but in our view, this should not delay surgery, as it can be done simultaneously in the operating room.

'Diagnosis-to-surgery' time at our institution is significantly longer than the other time-related variables, with a median time of $210 \mathrm{~min}$ or 3.5 hours, but not extremely different from the 4.3 hours reported by Harris et al. (2) As it is desirable to reduce this delay, an improvement in management with optimisation of organisation regarding operating room and personnel availability could be beneficial. There are reports on surgical delay to address malperfusion syndromes prior to surgery, by optimizing the flow in the true lumen, but most patients will benefit from immediate surgical treatment of the causative ATAAD (22).

Over time, we could not demonstrate a significant reduction in 'presentation-to-diagnosis' time or in 'onsetto-knife' time, which attributes to previous reports $(4,13)$.

Despite the fact that this was not the purpose of the study, we report a 30 -day mortality of $7.7 \%$ and an inhospital mortality of $11.5 \%$ proving that also smallvolume cardiothoracic centres can obtain excellent results. Nevertheless, there was no significant difference between short or long 'onset-to-knife' time or 'presentationto-diagnosis' time. This was also reported by Strauss et al. (15).

\section{Limitations}

This retrospective analysis covers a very heterogenous population, presenting with an ATAAD and the numbers available from this single network study (even over a 10-year period) limited the statistical power greatly to explore possible determinants of (diagnostic) delay and precluded meaningful analysis of the impact on mortality. As a result, assuming a direct cause and effect relationship should be done with caution. This study only highlights those cases in which the diagnosis and treatment of ATAAD is established. It is unclear how many cases of aortic dissection were missed within our referral network.

\section{Conclusions}

This report reveals the need for an ever high index of suspicion regarding the capricious clinical presentation of ATAAD by emergency personnel and improvement in logistics regarding the 'diagnosis-to-surgery' time. Early admission to the hospital followed by sharp and accurate diagnosis is a prerequisite for successful intervention in ATAAD. Owing to the time-dependent properties of ATAAD management, a (national) system of aortic dissection care should be implemented.

\section{Acknowledgments}

Funding: None.

\section{Footnote}

Provenance and Peer Review: This article was commissioned by the Guest Editors (Roberto Di Bartolomeo, Davide Pacini, Mohamad Bashir) for the series "the 10 th Postgraduate Course on 'Surgery of the Thoracic Aorta' in Bologna" published in Journal of Visualized Surgery. The article has undergone external peer review.

Reporting Checklist: The authors have completed the STROBE reporting checklist. Available at https://jovs. amegroups.com/article/view/10.21037/jovs-20-54/rc

Data Sharing Statement: Available at https://jovs.amegroups. com/article/view/10.21037/jovs-20-54/dss

Peer Review File: Available at https://jovs.amegroups.com/ 
article/view/10.21037/jovs-20-54/prf

Conflicts of Interest: All authors have completed the ICMJE uniform disclosure form (available at https://jovs. amegroups.com/article/view/10.21037/jovs-20-54/coif). The series "the 10th Postgraduate Course on 'Surgery of the Thoracic Aorta' in Bologna" was commissioned by the editorial office without any funding or sponsorship. The authors have no other conflicts of interest to declare.

Ethical Statement: The authors are accountable for all aspects of the work in ensuring that questions related to the accuracy or integrity of any part of the work are appropriately investigated and resolved. The study was conducted in accordance with the Declaration of Helsinki (as revised in 2013). Because of the retrospective design and the data retrieved from hospital medical record system only, informed consent was not required. The study was approved by the institutional ethics board at General Hospital SintJan, in Bruges, Belgium (B2020049000030).

Open Access Statement: This is an Open Access article distributed in accordance with the Creative Commons Attribution-NonCommercial-NoDerivs 4.0 International License (CC BY-NC-ND 4.0), which permits the noncommercial replication and distribution of the article with the strict proviso that no changes or edits are made and the original work is properly cited (including links to both the formal publication through the relevant DOI and the license). See: https://creativecommons.org/licenses/by-nc-nd/4.0/.

\section{References}

1. Spittell PC, Spittell JA Jr, Joyce JW, et al. Clinical features and differential diagnosis of aortic dissection: experience with 236 cases (1980 through 1990). Mayo Clin Proc 1993;68:642-51.

2. Harris KM, Strauss CE, Eagle KA, et al. Correlates of delayed recognition and treatment of acute type $\mathrm{A}$ aortic dissection: the International Registry of Acute Aortic Dissection (IRAD). Circulation 2011;124:1911-8.

3. Howard DP, Banerjee A, Fairhead JF, et al. Populationbased study of incidence and outcome of acute aortic dissection and premorbid risk factor control. Circulation 2013;127:2031-7.

4. Anagnostopoulos CE, Prabhakar MJ, Kittle CF. Aortic dissections and dissecting aneurysms. Am J Cardiol 1972;30:263-73.
5. Hirst AE Jr, Johns VJ Jr, Kime SW Jr. Dissecting aneurysm of the aorta: a review of 505 cases. Medicine (Baltimore) 1958;37:217-79.

6. Strauss C, Harris K, Hutchison S, et al. "Time is Life": Early mortality in type A acute aortic dissection: insights from the IRAD registry. J Am Coll Cardiol 2013;61:E1516.

7. Hagan PG, Nienaber CA, Isselbacher EM, et al. The International Registry of Acute Aortic Dissection (IRAD): new insights into an old disease. JAMA 2000;283:897-903.

8. Melvinsdottir IH, Lund SH, Agnarsson BA, et al. The incidence and mortality of acute thoracic aortic dissection: results from a whole nation study. Eur J Cardiothorac Surg 2016;50:1111-7.

9. Mészáros I, Mórocz J, Szlávi J, et al. Epidemiology and clinicopathology of aortic dissection. Chest 2000;117:1271-8.

10. Tsai TT, Nienaber CA, Eagle KA. Acute aortic syndromes. Circulation, 2005;112:3802-13.

11. Bickerstaff LK, Pairolero PC, Hollier LH, et al. Thoracic aortic aneurysms: a population-based study. Surgery 1982;92:1103-8.

12. Bavaria JE, Pochettino A, Brinster DR, et al. New paradigms and improved results for the surgical treatment of acute type A dissection. Ann Surg 2001;234:336-42; discussion 342-3.

13. Kocher KE, Meurer WJ, Fazel R, et al. National trends in use of computed tomography in the emergency department. Ann Emerg Med 2011;58:452-62.e3.

14. Hansen MS, Nogareda GJ, Hutchison SJ. Frequency of and inappropriate treatment of misdiagnosis of acute aortic dissection Am J Cardiol 2007;99:852-6.

15. Strauss C, Kebede T, Porten B, et al. Why the Delay? Identification of Factors Which Delay Diagnosis of Acute Aortic Dissection. Journal of the Minneapolis Heart Institute Foundation 2017;1:13-8.

16. Froehlich $\mathrm{W}$, Tolenaar J, Harris K, et al. Delay from diagnosis to surgery in transferred type A aortic dissection. Am J Med 2018;131:300-6.

17. Biagini E, Lofiego C, Ferlito M, et al. Frequency, determinants, and clinical relevance of acute coronary syndrome-like electrocardiographic findings in patients with acute aortic syndrome. Am J Cardiol 2007;100:1013-9.

18. Rapezzi C, Longhi S, Graziosi M, et al. Risk factors for diagnostic delay in acute aortic dissection. Am J Cardiol 2008;102:1399-406.

19. Hiratzka LF, Bakris GL, Beckman JA, et al. 2010 ACCF/AHA/AATS/ACR/ASA/SCA/SCAI/SIR/STS/ 
SVM guidelines for the diagnosis and management of patients with thoracic aortic disease. J Am Coll Cardiol 2010;55:e27-e129.

20. Collins JS, Evangelista A, Nienaber CA, et al. Differences in clinical presentation, management, and outcomes of acute type a aortic dissection in patients with and without previous cardiac surgery. Circulation 2004;110:II237-42.

21. Hirose H, Svensson L, Lytle B, et al. Aortic dissection after previous cardiovascular surgery. Ann Thorac Surg 2004;78:2099-105.

22. Deeb GM, Williams DM, Bolling SF, et al. Surgical delay for acute type A dissection with malperfusion. Ann Thorac Surg 1997;64:1669-75; discussion 1675-7.

23. Patel HJ, Williams DM, Dasika NL, et al. Operative delay for peripheral malperfusion syndrome in acute type A aortic dissection: a long-term analysis. J Thorac Cardiovasc Surg 2008;135:1288-95; discussion 1295-6.

24. Girdauskas E, Kuntze T, Borger M, et al. Surgical risk of preoperative malperfusion in acute type A aortic dissection. J Thorac Cardiovasc Surg 2009;138:1363-9.

25. Holmboe ES, Durning SJ. Assessing clinical reasoning:

doi: $10.21037 /$ jovs-20-54

Cite this article as: De Vos M, Ranschaert W, Vergauwen W, Graulus E, Verrelst P, Schepens M. Acute type A aortic dissection: timeline between onset and treatment. J Vis Surg $2021 ; 7: 24$. moving from in vitro to in vivo. Diagnosis (Berl)

2014;1:111-7.

26. Lecouturier J, Murtagh MJ, Thomson RG, et al. Response to symptoms of stroke in the UK: a systematic review. BMC Health Serv Res 2010;10:157.

27. Hansson EC, Geirsson A, Hjortdal V, et al. Preoperative dual antiplatelet therapy increases bleeding and transfusions but not mortality in acute aortic dissection type A repair. Eur J Cardiothorac Surg 2019;56:182-8.

28. von Kodolitsch Y, Schwartz A, Nienaber C. Clinical prediction of acute aortic dissection. Arch Intern Med 2000;160:2977-82.

29. Harris K, Strauss C. Diagnostic delay in acute aortic syndromes: how sensitive and specific are clinical features in disease recognition. Controversies in Aortic Dissection and Aneurysmal Disease. Springer, London 2014:107-14.

30. Garcia M, Mulvagh S, Bairey M, et al. Cardiovascular disease in women: clinical perspectives. Circ Res 2016;118:1273-93.

31. Weber T, Ho S, Auer J, et al. D-dimer in acute aortic dissection. Chest 2003;123:1375-8. 